\title{
Perioperative Antibiotic Prophylaxis and Antimicrobial Therapy of Intra-Abdominal Infections
}

\author{
Stefan Hagel ${ }^{a, b}, c$ Hubert Scheuerlein ${ }^{d}$ \\ ${ }^{a}$ Center for Infectious Diseases and Infection Control, Jena University Hospital, Jena, Germany, \\ ${ }^{b}$ Department of Internal Medicine IV, Gastroenterology, Hepatology and Infectious Diseases, Jena University Hospital, Jena, Germany, \\ ${ }^{c}$ Center for Sepsis Control \& Care (CSCC), Jena University Hospital, Jena, Germany, \\ ${ }^{\mathrm{d}}$ Department of General, Visceral and Vascular Surgery, Jena University Hospital, Jena, Germany
}

\section{Keywords}

Perioperative antibiotic prophylaxis .

Intra-abdominal infections - Antibiotic resistance

\section{Summary}

Background: The increase of antimicrobial resistances to first- and second-line antibiotics, especially of Gram-negative bacteria, and the lack of novel antimicrobial substances are a challenge in the treatment of intra-abdominal infections. Methods: Review article. Results: The efficacy and safety of perioperative antibiotic prophylaxis in visceral surgery has been demonstrated by several meta-analyses. Perioperative antibiotic prophylaxis is defined as a single administration of antibiotics shortly before a surgical intervention. A so-called prolonged prophylaxis including the postoperative period (e.g. 1-3 days postoperatively) should be avoided as it does not reduce the number of wound infections and is associated with an increased risk of antimicrobial resistance and side effects. Antimicrobial management of severe intra-abdominal infections involves a delicate balance of optimizing empirical therapy which has been shown to improve outcomes while simultaneously reducing unnecessary use of antimicrobials. Conclusion: Antimicrobial resistance poses a serious threat to human health and requires a rational use of antibiotics to curb further spreading. This applies for perioperative prophylaxis as well as for the treatment of intra-abdominal infections.

\author{
Schlüsselwörter \\ Perioperative Antibiotikaprophylaxe . \\ Intraabdominelle Infektionen - Antibiotikaresistenz
}

\section{Zusammenfassung}

Hintergrund: Die Zunahme von Resistenzen gegen «Erstund Zweitlinien-Antibiotika" (z.B. $\beta$-Laktam Antibiotika, Fluorchinolone und Aminoglykoside), vor allem von Gramnegativen Erregern, und das Fehlen neuer Substanzen erschweren die Behandlung von intraabdominellen Infektionen und stellen eine zunehmende Herausforderung für den Chirurgen im Alltag dar. Methoden: Übersichtsarbeit. Ergebnisse: Die Wirksamkeit und Sicherheit der perioperativen Antibiotikaprophylaxe in der Viszeralchirurgie ist auf breiter Basis durch Metaanalysen abgesichert. Die perioperative Antibiotikatherapie ist definiert als die einmalige Antibiotikagabe kurz vor einem operativen Eingriff. Die über die Operation hinausgehende, sogenannte verlängerte Prophylaxe (z.B. 1-3 Tage postoperativ) soll unterbleiben, da sie in keiner Weise geeignet ist, die Zahl der Wundinfektionen zu verringern, und mit einem erhöhten Resistenz- und Nebenwirkungsrisiko einhergeht. Die Therapie von intraabdominellen Infektionen erfordert eine breite empirische antimikrobielle Therapie, da eine frühzeitige resistenzgerechte Therapie mit einer niedrigeren Mortalität einhergeht. Gleichzeitig sollte jedoch der unkritische breite Antibiotikaeinsatz vermieden werden, um die weitere Entwicklung und Ausbreitung von Antibiotikaresistenzen zu verhindern. Schlussfolgerung: Die Zunahme von Antibiotikaresistenzen stellt eine zunehmende Bedrohung dar und erfordert einen rationalen Umgang mit Antibiotika, um die weitere Ausbreitung zu verlangsamen. Dies trifft sowohl für die perioperative Antibiotikaprophylaxe als auch für die Therapie intraabdomineller Infektionen zu.

\section{KARGER \\ Fax +497614520714

\section{(C) 2014 S. Karger GmbH, Freiburg}

$1662-6664 / 14 / 0305-0310 \$ 39.50 / 0$
Dr. med. Stefan Hagel

Zentrum für Infektionsmedizin und Krankenhaushygiene

Klinik für Innere Medizin IV (Gastroenterologie, Hepatologie, Infektiologie)

Universitätsklinikum Jena

Erlanger Allee 101, 07740 Jena, Germany

Stefan.Hagel@med.uni-jena.de 


\section{Perioperative Antibiotic Prophylaxis}

In the second national prevalence study on the frequency of healthcare-associated infections and use of antibiotics in Germany, surgical wound infections were the most frequent type of healthcare-associated infections, accounting for $24 \%$ of the cases [1]. The wound infection rate after aseptic interventions is in the range of 5\%, while it is as high as $40 \%$ after abdominal interventions with contamination (colorectal surgery) $[2,3]$. Every postoperative infection increases the risk of further complications and the suffering of the individual patient. The efficacy and safety of perioperative antibiotic prophylaxis to reduce surgical wound infections in visceral surgery has been demonstrated by several meta-analyses. Due to the economic burden of postoperative wound infections, perioperative antibiotic prophylaxis is also of major importance as it reduces the duration of the hospital stay by preventing infections. The necessity of outpatient follow-up treatment can also be reduced.

The decision for perioperative antibiotic prophylaxis is made according to a number of risk factors, in particular in aseptic interventions (table 1). The degree of potential contamination of the surgical field (clean, clean-contaminated, contaminated, dirty), prolonged duration of surgery, implantation of biomaterials, and comorbidity need to be considered $[4,5]$. Perioperative antibiotic prophylaxis is administered in a risk-adapted individualized manner. The antibiotics selected for prophylaxis must cover the expected pathogens for that operative site, and the choice of antibiotic should take local resistance patterns into account. The broadest experience is in the area of $\beta$-Lactam antibiotics [4]. For our own practice, we have developed a recommendation scheme based on the recommendations in the current literature (table 2).

For surgical procedures, intravenous prophylactic antibiotics should be given within $60 \mathrm{~min}$ before the skin is incised and as close to the time of incision as practically possible. For operative durations up to $3 \mathrm{~h}$, the one-time administration of an antibiotic ('single shot') is sufficient. In prolonged surgery ( $>3 \mathrm{~h}$ ) or massive blood loss $(>1,500 \mathrm{ml})$, a repeated intra-operative administration is necessary [6]. Any further administration of antibiotics is defined as treatment, not as prophylaxis [7]. Such prolonged administration is not associated with a reduced wound infection rate. Hirokawa et al. [8] randomly assigned patients undergoing scheduled liver resection to either prolonged postoperative antibiotic prophylaxis for 3 days after the operation or single-shot antibiotic prophylaxis. There were no significant differences between the two groups regarding signs of surgical site infection (10.6 vs. $13.8 \%, \mathrm{p}=$ $0.66)$ and remote site infection ( 2.1 vs. $8.5 \%, p=0.1)$ [8]. In fact, prolonged perioperative antibiotic prophylaxis is associated with an increased risk of Clostridium difficile-associated infection (CDI) and correlates with an increased risk of acquired antibiotic resistance. In a retrospective cohort study with 7,600 episodes of perioperative antibiotic prophylaxis,
Table 1. Risk factors for postoperative wound infections (modified according to 'Recommendations of an expert commission of the Paul Ehrlich Society for Chemotherapy' [14])

\section{Patient-related factors}

Age (increase per decennium)

Diabetes mellitus

Compromised immunity/immunosuppression

Poor general condition, malnutrition

Obesity

ASA score $>$ II

MRSA/MSSA carrier

Fever (1 week preoperatively)

Women: for interventions on the colon and cardiac surgery

Hemodialysis

Hepatitis, cirrhosis

Stoma

Drug abuse

Infections in other locations

Arterial ischemia

Peripheral edema

Lymphangitis

Neuropathy

Previous antibiotic treatment

Smoking

Left ventricular failure after coronary artery bypass graft

Bacterial translocation in laparotomy

\begin{tabular}{|c|}
\hline \multirow{2}{*}{$\begin{array}{l}\text { Surgery-related factors } \\
\text { Preoperatively }\end{array}$} \\
\hline \\
\hline Emergency surgery \\
\hline Prolonged preoperative hospitalization \\
\hline Wrong choice of perioperative antibiotic prophylaxis \\
\hline Wrong timing of perioperative antibiotic prophylaxis \\
\hline Wound classified as contaminated/dirty \\
\hline Previous radiation therapy \\
\hline High-risk surgery \\
\hline Reinterventions \\
\hline Stones in the biliary duct, biliary duct obstruction \\
\hline Elevated C-reactive protein \\
\hline Biomaterials implantation \\
\hline Shave not immediately prior to surgery \\
\hline Preoperative urinary catheter \\
\hline Intraoperatively \\
\hline Surgeons' experience \\
\hline Duration of surgery $>2 \mathrm{~h}$ (increase per hour) \\
\hline Infected surgical field \\
\hline Contaminated surgical field \\
\hline Blood transfusion, albumin administration \\
\hline Prolonged duration of anesthesia \\
\hline More than one surgical intervention \\
\hline Diathermy \\
\hline Decreased oxygen saturation \\
\hline Hypothermia \\
\hline Wound stapler \\
\hline Unpredictable complications \\
\hline Surgical technique \\
\hline Ineffective blood concentration of the drug \\
\hline Conversion from laparoscopy to laparotomy \\
\hline $\begin{array}{l}\text { Wound contamination with Enterococcus, enterobacteria, } \\
\text { Bacteroides fragilis }\end{array}$ \\
\hline Postoperatively \\
\hline Drainage device $>3$ days \\
\hline Respiratory sepsis \\
\hline $\begin{array}{l}\text { Invasive interventions, urinary catheter, chest drain, nasal tube, } \\
\text { central venous catheter }\end{array}$ \\
\hline Hemodialysis \\
\hline Previous reoperation for hemorrhages \\
\hline
\end{tabular}


Table 2. Recommendations for perioperative antibiotic prophylaxis at the University Hospital Jena

\begin{tabular}{lll}
\hline Procedure & First choice & Alternative \\
\hline $\begin{array}{l}\text { Oesophagus/pancreas/ } \\
\text { liver surgery }\end{array}$ & cefuroxime + metronidazole & $\begin{array}{c}\text { clindamycin }+ \text { gentamicin or } \\
\text { ciprofloxacin }+ \text { metronidazole }\end{array}$ \\
$\begin{array}{l}\text { Liver transplantation } \\
\text { ceftriaxone }+ \text { metronidazole }+\end{array}$ & \\
$\begin{array}{l}\text { Colorectal surgery } \\
\text { Appendix }\end{array}$ & $\begin{array}{l}\text { cefuroxime }+ \text { metronidazole } \\
\text { cefuroxime }+ \text { metronidazole }\end{array}$ & $\begin{array}{l}\text { clindamycin }+ \text { gentamicin } \\
\text { clindamycin }+ \text { gentamicin } \\
\text { cholecystectomy) }\end{array}$ \\
\hline
\end{tabular}

an contrast, the national clinical guideline SIGN 104 - 'Antibiotic prophylaxis in surgery' - of the Scottish Intercollegiate Guidelines Network recommends that antibiotic prophylaxis should be considered in high-risk patients (i.e. intraoperative cholangiogram, bile spillage, conversion to laparotomy, acute cholecystitis/pancreatitis, jaundice, pregnancy, immunosuppression, insertion of prosthetic devices).
$1.5 \%$ of the patients who received perioperative antibiotic prophylaxis as their only antibiotic treatment developed CDI [9]. Harbarth et al. [10] compared the effect of short $(<48 \mathrm{~h})$ versus prolonged $(>48 \mathrm{~h})$ perioperative antibiotic prophylaxis on surgical site infections and acquired antimicrobial resistance in an observational 4-year cohort study in 2,641 patients who underwent coronary artery bypass graft surgery. After adjustment for possible confounding factors, prolonged perioperative antibiotic prophylaxis was not associated with a decreased risk of surgical site infections (adjusted odds ratio (OR): 1.2; confidence interval (CI): 0.8-1.6) but was correlated with an increased risk of isolation of enterobacteriaceae or enterococci with acquired resistance to the administered prophylactic agent (i.e. cephalosporins or vancomycin) (adjusted OR: 1.6; CI: 1.1-2.6) [10]. Although evidence shows that prolonged perioperative antibiotic prophylaxis is ineffective in reducing surgical site infections, increases antimicrobial resistance, and aggravates the risk for CDI, this practice is still widespread. In the above-mentioned European Centre for Disease Prevention and Control (ECDC) point prevalence survey of healthcare-associated infections and antimicrobial use in European hospitals, perioperative antibiotic prophylaxis was administered for more than 1 day in 59\% of the cases (country range: 10.7-92.3\%). Considering Germany alone, more than $70 \%$ of all perioperative antibiotic prophylaxes were administered for more than 1 day [1].

As a consequence, the DGAV (Deutsche Gesellschaft für Allgemein- und Viszeralchirurgie/German Society for General and Visceral Surgery) has recently developed the following plan [11]:

- Depending on the operation, the proper antibiotic agent needs to be selected with the correct dosage. Thus, on the basis of local resistance patterns, an interdisciplinary group shall determine the drugs for perioperative antibiotic prophylaxis once per year. Interventions for which no antibiotic prophylaxis is required shall also be clearly defined.

- The administration of the perioperative antibiotic prophylaxis shall be the responsibility of the anesthetist. This safeguards that the drugs are reliably administered 60-30 min prior to the intervention.

- For an operative duration of less than $3 \mathrm{~h}$, a single administration of an antibiotic ('single shot') is sufficient. Only prolonged operations or massive blood loss justify the repeated intraoperative administration.

- The so-called prolonged prophylaxis beyond the operation (e.g. 1-3 days postoperatively) shall not be administered as it does not reduce the number of wound infections.

The national clinical guideline SIGN 104 - 'Antibiotic Prophylaxis in Surgery' - of the Scottish Intercollegiate Guidelines Network provides a very good current overview of perioperative antibiotic prophylaxis (http://sign.ac.uk/guidelines/index.html).

\section{Intra-Abdominal Infections}

Intra-abdominal infections (IAIs) are frequently a challenge for medical professionals in visceral surgery. In Germany, approximately 150,000 patients are being treated for this condition each year [12]. While the lungs are the most frequent focus of infections, IAIs are the second-most frequent type of infections in patients with severe sepsis and septic shock as well as the second-most frequent cause of death from infections in the intensive care unit $[13,14]$. Unfortunately, there is no consensus in the literature with respect to the classification of IAIs, and there are different parallel and in some cases overlapping classification systems. The Anglo-American literature in particular distinguishes between uncomplicated and complicated IAIs. According to the guidelines of the Surgical Infection Society (SIS) and the Infectious Diseases Society of America (IDSA), a complicated intra-abdominal infection (cIAI) extends beyond the hollow organ of origin into the peritoneal space and is associated with either abscess formation or peritonitis. Uncomplicated infection involves intramural inflammation of the gastrointestinal tract and has a substantial probability of progressing to complicated infection if 
not adequately treated. Uncomplicated IAIs can only be cured by means of antimicrobial treatment, while complicated IAIs require additional surgical and/or interventional treatment as they are being complicated by either abscess formation or local or diffuse peritonitis. Most cases of postoperative infections get classified as complicated IAIs. Furthermore, the IDSA guidelines distinguish between hospital-acquired and community-acquired infections and also define the severity of community-acquired infections (mild, moderate, and severe) [14]. However, this classification only partially takes into account the risk factors for resistant microbes which may also cause bland infections, and it does not specify the clinical severity of hospital-acquired infections. The range of microbes causing community-acquired IAIs is different from those causing hospital-acquired IAIs - in the latter case the proportion of multiresistant bacteria is markedly higher [12].

In contrast to the classification between complicated and uncomplicated IAIs, several authors recommend a classification of peritonitis, which is among the most frequent IAIs, into three different forms [15]:

- Primary peritonitis (hematogenous peritonitis in children, spontaneous bacterial peritonitis (SBP) in adults, tuberculous peritonitis).

- Secondary peritonitis (perforation peritonitis, postoperative peritonitis, posttraumatic peritonitis).

- Tertiary peritonitis (persistent peritonitis often with less virulent or in immunocompetent patients non-pathogenic microbes, e.g. fungal peritonitis).

Secondary peritonitis may be classified as community- and hospital-acquired postoperative varieties (e.g. anastomotic insufficiency after anterior rectum resection). As opposed to tertiary peritonitis, in postoperative peritonitis there is a disease that requires surgical or interventional treatment. In tertiary peritonitis, the infection of the abdominal cavity persists after surgical treatment of the focal lesion that has initially caused the peritonitis. In addition, there are special clinical presentations, such as peritonitis in continuous ambulatory peritoneal dialysis (CAPD) and Candida peritonitis. In the surgical context, peritonitis does not only mean bacterial contamination of the abdominal cavity but also complex reactions of the organ 'peritoneum' as such with all the consequences for the organism [16].

From the surgical point of view, the most relevant form of peritonitis is secondary peritonitis with postoperative peritonitis as a hospital-acquired infection in particular. Most patients have undergone antibiotic treatment or received perioperative antibiotic prophylaxis at the time of disease manifestation. Thus, as a consequence of selection pressure, postoperative peritonitis is caused by multidrug-resistant, Gram-negative and Gram-positive bacteria, enterococci (including vancomycin-resistant enterococci (VRE)), and possibly fungi in a greater proportion. Pseudomonas are rarely causative agents for postoperative peritonitis [17]. Independent of the location of origin of the bacterial contamination, postoperative peritonitis is a polymicrobial infection with facultative aerobic enterobacteriaceae (e.g. Escherichia coli, Klebsiella spp., Citrobacter spp., Enterococcus spp.) and obligate anaerobic bacteria (e.g. Bacteroides spp., Peptostreptococci, Clostridium spp.). Infections originating from the stomach, duodenum, bile ducts, or proximal small intestine are mostly caused by Gram-positive and Gram-negative facultative aerobic bacteria. Infections originating from the ileum are mainly caused by facultative aerobic and obligate aerobic Gram-negative bacteria (such as e.g. Bacteroides fragilis). In case of the colon being the origin, facultative and obligate anaerobic microbes are predominant (often enterococci, most often E. coli) [16].

Antimicrobial management of severe IAIs involves a delicate balance of optimizing empirical therapy, which has been shown to improve clinical outcomes, while at the same time reducing unnecessary use of antimicrobial drugs. The increase of antimicrobial resistances and the lack of novel antimicrobial substances complicate this process. While Methicillin-resistant Staphylococcus aureus (MRSA) was considered to be the biggest challenge in the 1990s, it is now the multiresistant, Gram-negative bacteria and VRE for which the therapeutic options are limited. The development of a new antibiotic drug from bench to bedside takes 8-10 years so that the number of antibiotics will be limited in the near future. Thus, the term 'postantibiotic era' is increasingly used [18].

\section{MRSA (Methicillin-Resistant S. Aureus)}

Worldwide, infections with MRSA are decreasing or stagnant. In a current study, Meyer et al. [19] have analyzed data from the German hospital infection surveillance system (KISS) between 2007 and 2012. They found a significant decrease from 33 to $27 \%$ of the MRSA proportion in hospitalacquired $S$. aureus infections. Current data from the USA report about a decrease of $31 \%$ of invasive MRSA infections between 2005 and 2011. In the UK, a decrease of $69 \%$ could be found and was thus even more pronounced. The reasons for the decrease are unclear. They are possibly due to interventions and/or may be related to the biology of the microbes [19]. As opposed to respiratory and wound infections, MRSA has a minor impact in IAIs. According to the IDSA guideline for IAIs, empiric antimicrobial coverage directed against MRSA should only be provided to patients with healthcare-associated IAIs who are known to be colonized with the organism or who are at risk of having an infection due to this organism because of prior treatment failure and significant antibiotic exposure. Vancomycin is recommended for the treatment of suspected or proven IAIs due to MRSA [14]. Besides vancomycin, tigecycline is approved for IAIs, and there exist several meta-analyses on its efficacy in IAIs (table 3). Practical experience also shows that tigecycline, when given alone or in combination with other antibacterial drugs, appears to be efficacious against multiple pathogens, with clinical response rates in approximately $80 \%$ of the patients with cIAI [20]. 
Table 3. Overview of new antibiotics effective against MRSA

\begin{tabular}{|c|c|c|c|c|}
\hline & Linezolid & Tigecyclin & Daptomycin & Ceftarolin \\
\hline Class & oxazolidinone & glycylcycline & lipopeptides & group 5 cephalosporin \\
\hline $\begin{array}{l}\text { Bioavailability after } \\
\text { oral application }\end{array}$ & almost $100 \%$ & i.v. only & i.v. only & i.v. only \\
\hline Mechanism of action & protein synthesis & protein synthesis & membrane pores & blocking of cell wall synthesis \\
\hline Effect & bacteriostatic & bacteriostatic & bactericidal & bactericidal \\
\hline Spectrum & Gram-positive & $\begin{array}{l}\text { Gram-positive and } \\
\text { Gram-negative (not } \\
\text { Pseudomonas spp. and } \\
\text { Proteus spp.) }\end{array}$ & Gram-positive & $\begin{array}{l}\text { Gram-positive, including } \\
\text { MRSA, and Gram-negative } \\
\text { (not ESBL and non-fermenter, } \\
\text { such as Pseudomonas aeruginosa) }\end{array}$ \\
\hline Side effects & $\begin{array}{l}\text { thrombocytopenia, } \\
\text { polyneuropathy }\end{array}$ & nausea, vomiting & $\begin{array}{l}\text { rhabdomyolysis, eosinophilic } \\
\text { pneumonia }\end{array}$ & nausea, vomiting \\
\hline Approved indications & pneumonia, cSSSI ${ }^{\mathrm{a}}$ & $\begin{array}{l}\mathrm{cSSSI}^{\mathrm{a}} \text {, intra-abdominal } \\
\text { infections }\end{array}$ & $\begin{array}{l}\text { cSSSI}^{\mathrm{a}}, \text { (right ventricular) } \\
\text { endocarditis from MRSA, } \\
\text { MRSA bacteremia }\end{array}$ & $\begin{array}{l}\text { community-acquired pneumonia } \\
\text { (non-MRSA), } \text { cSSSI }^{\mathrm{a}}\end{array}$ \\
\hline
\end{tabular}

${ }^{\mathrm{a} C o m p l i c a t e d ~ s k i n ~ a n d ~ s k i n ~ s t r u c t u r e ~ i n f e c t i o n s . ~}$

\section{ESBL-Expressing Enterobacteriaceae}

Members of the family enterobacteriaceae commonly express plasmid-encoded $\beta$-lactamases (e.g. TEM-1, TEM-2, and SHV-1), which confer resistance to penicillins but not to expanded-spectrum cephalosporins (e.g. third-generation cephalosporins). In 1979, however, a new group of enzymes, the extended-spectrum $\beta$-lactamases (ESBLs), was first detected. ESBLs are $\beta$-lactamases that hydrolyze these expanded-spectrum cephalosporins in addition to other penicillins. Because they are located on plasmids, ESBLs are interchangeable between Gram-negative bacteria. Very broad antibiotic resistance of ESBL-producing bacteria extending to multiple antibiotic classes, including fluoroquinolones and aminoglycosides, has become an increasing problem in Europe as well as worldwide over the last decade. As a result, carbapenems, tigecycline, and colistin are often the only remaining treatment options. The proportion of ESBL-producing E. coli and Klebsiella spp. has increased from less than $1 \%$ to more than $20 \%$ in many places. The excess use of thirdgeneration cephalosporins and fluoroquinolones appears to promote the prevalence of ESBL. Risk factors for an ESBL infection are in particular hospitalization and a stay in the intensive care unit, residence at a nursing home, central venous catheter, urinary catheter, and chronic hemodialysis [21].

\section{Carbapenemase-Producing Bacteria}

The spread of carbapenem-non-susceptible bacteria, more specifically of carbapenemase-producing enterobacteriaceae and carbapenem-resistant Acinetobacter baumannii, is a threat to healthcare and patient safety worldwide. In particular, Klebsiella pneumoniae carbapenemases (KPC) have spread globally since the first report in 1990. In Germany, however, Oxa-48- $\beta$ carbapenemases are currently more frequent than KPC [22]. Carbapenemases appear in almost all cases in combination with ESBL so that treatment consists primarily of antibiotic combinations including tigecycline, colistin, gentamicin, and possibly a carbapenem (depending on the minimal inhibitory concentration of the causative agent). According to clinical observation studies, antibiotic combination therapy in infections with carbapenemase-producing bacteria require high therapeutic dosages which are in certain cases above the recommended and approved dosages [23], e.g. tigecycline $2 \times 100 \mathrm{mg}$ i.v., colistin $3 \times 3$ million IU i.v. ('loading dose' of 9 million IU i.v.), and gentamicin $1 \times 5-7 \mathrm{mg} / \mathrm{kg}$ body weight i.v. once daily.

In countries where carbapenemase-producing bacteria are endemic (e.g. Greece, Italy, Israel) it is well known that especially $K$. pneumoniae has a high potential for transmission within hospitals. This is confirmed by a recently terminated outbreak at the university hospital in Leipzig. There, the largest KPC outbreak reported in Germany so far occurred between July 2010 and June 2013 when a total of 103 patients were either colonized (58\%) or infected (42\%) with KPC2-producing K. pneumoniae (KPC-2-KP). The outbreak was caused by the admission of a 66-year-old patient who was transferred from a hospital in Rhodes (Greece) where he had contracted a hospital-acquired pneumonia. There, KPC-producing Klebsiella species are highly endemic. Molecular genetic testing suggested that in individual cases a single night in a room with multiple patients of whom one was later tested positive for KPC was sufficient for microbe transmission to other patients. In a matched-pair analysis, the clinical data of 9 KPC-positive liver transplant recipients (LTR) have been compared with the data from 18 KPC-negative LTRs. $89 \%$ of the KPC-positive LTRs developed infections with KPC-2-KP (pneumonia: $4 / 9$, peritonitis: $2 / 9$, postoperative wound infection: $2 / 9)$, and $56 \%(5 / 9)$ had a positive blood culture. The univariate analysis showed a significant difference in in-hospital mortality, with increased mortality in the KPC-positive LTRs (78 vs. $11 \%, \mathrm{p}=0.001)$ and a relative risk of death related to KPC-2-KP infection of 7.0 (95\% CI: 1.8-27.1) [24, 25]. 
Table 4. Clinical constellations requiring calculated treatment effective against enterococci (modified according to [14])

\begin{tabular}{|c|c|c|}
\hline & Clinical constellation & Calculated treatment \\
\hline $\begin{array}{c}\text { Enterococcus } \\
\text { faecalis }\end{array}$ & $\begin{array}{l}\text { manifestation in intraoperative sample } \\
\text { and/or blood culture; } \\
\text { hospital-acquired infections or postoperative } \\
\text { infections after previous antibiotic treatment } \\
\text { (in particular cephalosporines); } \\
\text { immunosuppression; } \\
\text { artificial heart valves or vascular prostheses }\end{array}$ & $\begin{array}{l}\text { amoxicillin/ampicillin; } \\
\text { piperacillin (/tazobactam); } \\
\text { imipenem }\end{array}$ \\
\hline+ VRE & $\begin{array}{l}\text { known VRE colonization; } \\
\text { post liver transplantation and hepatobiliary } \\
\text { infection }\end{array}$ & $\begin{array}{l}\text { linezolid, tigecycline, } \\
\text { daptomycin }\end{array}$ \\
\hline
\end{tabular}

\section{Vancomycin-Resistant Enterococci (VRE)}

The clinical relevance of detection of enterococci in patients with IAI is discussed controversially. In general, enterococci are less virulent than enterobacteriaceae. Detection of enterococci in tracheal aspirate, for example, is generally considered as colonization only. However, detection of the species in sterile samples should generally lead to targeted therapy. In most cases, only linezolid, tigecycline, and daptomycin can be used against VRE (usually Enterococcus faecium). Table 4 shows clinical constellations requiring calculated treatment that is effective against enterococci [14].

\section{Candida Species}

Similar to enterococci, Candida is not to be considered necessarily as a pathogen in IAI. Candida spp. are cultured from $20 \%$ of the patients with acute perforations of the gastrointestinal tract. Even when there is evidence of fungi, antifungal agents are unnecessary in adults unless the patient has recently received immunosuppressive therapy for a neoplasm, has a perforation of a gastric ulcer on acid suppression, or shows malignancy, inflammatory disease, or postoperative or recurrent IAI. Fluconazole is an appropriate choice for treatment if Candida albicans is isolated. For fluconazole-resistant Candida species, treatment with an echinocandin (caspofungin, micafungin, or anidulafungin) is appropriate. For the critically ill patient, initial treatment with an echinocandin instead of a triazole is recommended [14]. In case of candidemia, all catheters should be changed, a fundoscopy should be performed in all cases as there are frequently septic abscesses, and treatment should be continued for at least 14 days after the first negative blood culture. In the case of organ involvement, a 12-week treatment is the standard [26].

\section{Calculated Treatment}

It is impossible to give general recommendations concerning the selection of a certain class of antimicrobial chemotherapeutics since all available clinical trials were designed to prove noninferiority to the comparator product and because of heterogenous clinical study data [16]. Nevertheless, several societies developed guidelines and recommendations based on the multitude of clinical trials investigating antimicrobial chemotherapeutics. Amongst others, the Paul Ehrlich Society/Infektliga have developed recommendations for antibiotic treatment based on American guidelines [21]. For secondary peritonitis, there are the following scenarios:

- Locally contained situation, sterile or low number of microbes, clear or slightly frothy secretions (e.g. acute gastric perforation, acute cholecysitis, acutely perforated appendicitis): aminopenicillin/BLI or acylaminopenicillin/BLI; alternatives: cephalosporin group $2+$ metronidazole, cephalosporin group $3 \mathrm{a}+$ metronidazole, carbapenem group 2. Duration of treatment: Short-term treatment (1-2 days) often sufficient.

- Diffuse peritonitis, duration of the peritonitis $>2-4 \mathrm{~h}$, medium number of microbes, frothy/fecal secretions: acylaminopenicillin/BLI, carbapenem group 1/2, cephalosporin group $3 / 4$, or fluoroquinolone group 2 , each with metronidazole; fluoroquinolone group 4; tigecycline. Duration of treatment: 5-7 days depending on clinical and microbiological findings and organ function (bowel).

- Postoperative peritonitis: carbapenem group 1/2, acylaminopenicillin/BLI, cephalosporin group 4, with metronidazole; tigecycline. Duration of treatment: 10-14 days.

Patient-specific risk factors including severe comorbidities, previous antibiotic treatment (last 3 months), duration of preoperative hospitalization, travel history, known colonization with multiresistant microbes, and local resistance patterns have to be considered when making individual choices in the initial empiric treatment. The risk of developing resistance should be reduced by a so called de-escalation treatment: following initial broad, calculated antibiotic treatment, this will be changed to a narrow-spectrum antibiotic according to the microbiological findings. Empiric coverage of Enterococcus and empiric antifungal therapy for Candida are both not recommended in patients with community-acquired IAI. Antifungal therapy for patients with severe community-acquired or healthcare-associated infection is recommended if Candida is grown from intraabdominal cultures. For the critically ill patient, initial therapy with an echinocandin instead of a triazole is recommended [14]. 


\section{Conclusion}

Antimicrobial management of severe IAIs involves a delicate balance of optimizing empirical therapy, which has been shown to improve clinical outcomes, while at the same time reducing unnecessary use of antimicrobial drugs to curb further spreading of antimicrobial resistance. For the same reason, prolonged perioperative antibiotic prophylaxis should be particularly avoided as it is not associated with a reduced wound infection rate but an increased risk for CDI and acquired antibiotic resistance.

\section{Disclosure Statement}

SH: Lecture fees from Pfizer Pharma $\mathrm{GmbH}$, Astra Zeneca, und MSD. HS: No conflict of interest.

\section{References}

1 Behnke M, Hansen S, Leistner R, et al: Nosocomial infection and antibiotic use: a second national prevalence study in Germany. Dtsch Arztebl Int 2013;110:627-633.

2 Bratzler DW, Dellinger EP, Olsen KM, et al: Clinical practice guidelines for antimicrobial prophylaxis in surgery. Am J Health Syst Pharm 2013;70: 195-283.

3 Rovera F, Diurni M, Dionigi G, et al: Antibiotic prophylaxis in colorectal surgery. Expert Rev Anti Infect Ther 2005;3:787-795.

4 Wacha H, Isenmann R, Kujath P, Lebert C, Naber CK, Salzberger B: Perioperative AntibiotikaProphylaxe: Empfehlungen einer Expertenkommission der Paul-Ehrlich-Gesellschaft für Chemotherapie e.V. Chemother J 2010;19:70-84.

5 Cruse PJ, Foord R: The epidemiology of wound infection. A 10-year prospective study of 62,939 wounds. Surg Clin North Am 1980;60:27-40.

6 Scottish Intercollegiate Guidelines Network (SIGN): Antibiotic Prophylaxis in Surgery. Edinburgh, SIGN, 2008.

7 Knebel P, Weigand MA, Büchler MW, Seiler CM Evidence-based antibiotic prophylaxis in general and visceral surgery (article in German). Chirurg 2011;82:227-234.

8 Hirokawa F, Hayashi M, Miyamoto Y, et al: Evaluation of postoperative antibiotic prophylaxis after liver resection: a randomized controlled trial. Am J Surg 2013;206:8-15.

-9 Carignan A, Allard C, Pépin J, Cossette B, Nault V, Valiquette L: Risk of Clostridium difficile infection after perioperative antibacterial prophylaxis before and during an outbreak of infection due to a hypervirulent strain. Clin Infect Dis 2008;46:18381843
10 Harbarth S, Samore MH, Lichtenberg D, Carmeli Y: Prolonged antibiotic prophylaxis after cardiovascular surgery and its effect on surgical site infections and antimicrobial resistance. Circulation 2000;101:2916-2921.

11 Zylka-Menhorn V: Zu einem guten Chirurgen gehört die saubere Indikationsstellung. Dtsch Ärztebl 2014;111:692-693.

12 Bodmann K-F: Komplizierte intraabdominelle Infektionen: Erreger, Resistenzen. Chirurg 2010;81: 38-49.

13 Engel C, Brunkhorst FM, Bone H-G, et al: Epidemiology of sepsis in Germany: results from a national prospective multicenter study. Intensive Care Med 2007;33:606-618.

14 Solomkin JS, Mazuski JE, Bradley JS, et al: Diagnosis and management of complicated intra-abdominal infection in adults and children: guidelines by the Surgical Infection Society and the Infectious Diseases Society of America. Surg Infect 2010;11: 79-109.

15 Eckmann C, Dryden M, Montravers P, Kozlov R, Sganga G: Antimicrobial treatment of 'complicated' intra-abdominal infections and the new IDSA guidelines? A commentary and an alternative European approach according to clinical definitions. Eur J Med Res 2011;16:115-126.

16 Kujath P, Hoffmann M, Rodloff A: Antimicrobial and antimycotic therapy of intra-abdominal infections (article in German). Chirurg 2008;79:295-305.

17 Augustin P, Tran-Dinh A, Valin N, et al: Pseudomonas aeruginosa post-operative peritonitis: clinical features, risk factors, and prognosis. Surg Infect 201314;14:297-303.

18 Boucher HW, Talbot GH, Bradley JS, et al: Bad bugs, no drugs: no ESKAPE! An Update from the Infectious Diseases Society of America. Clin Infect Dis 2009;48:1-12.
19 Meyer E, Schröder C, Gastmeier P, Geffers C: The reduction of nosocomial MRSA infection in Germany - an analysis of data from the Hospital Infection Surveillance System (KISS) between 2007 and 2012. Dtsch Arztebl 2014;111:331-336.

20 Bassetti M, Eckmann C, Bodmann KF, et al: Prescription behaviours for tigecycline in real-life clinical practice from five European observational studies. J Antimicrob Chemother 2013;68(suppl 2):ii5-14.

21 Bodmann K-F, und die Expertenkommission der Infektliga: Complicated intra-abdominal infections: pathogens, resistance. Recommendations of the Infectliga on antbiotic therapy (article in German). Chirurg 2010;81:38-49.

22 Kaase M: Bericht des NRZ für gramnegative Krankenhauserreger. Carbapenemase-tragende gramnegative Erreger im Zeitraum Mai bis Juni 2010. Epidemiol Bull 2010;28:267.

23 Ben-David D, Kordevani R, Keller N, et al: Outcome of carbapenem resistant Klebsiella pneumoniae bloodstream infections. Clin Microbiol Infect 2012;18:54-60.

24 Lübbert C, Rodloff AC, Laudi S, et al: Lessons learned from excess mortality associated with Klebsiella pneumoniae carbapenemase 2-producing K. pneumoniae in liver transplant recipients. Liver Transpl 2014;20:736-738.

25 Lübbert C, Becker-Rux D, Rodloff AC, et al: Colonization of liver transplant recipients with KPCproducing Klebsiella pneumoniae is associated with high infection rates and excess mortality: a casecontrol analysis. Infection 2014;42:309-316.

26 Cuenca-Estrella M, Verweij PE, Arendrup MC, et al: ESCMID guideline for the diagnosis and management of Candida diseases 2012: diagnostic procedures. Clin Microbiol Infect 2012;18(suppl 7):918 . 